\title{
Uso de resíduos sólidos de estação de tratamento de água como carga em blocos cerâmicos
}

\author{
E.L.G. da Silva ${ }^{1}$, A.P. Maciel ${ }^{1,2}$ \\ ${ }^{1}$ Universidade Federal do Maranhão, Programa de Pós-graduação em Energia e Ambiente, Av. Portugueses, 1966, 65085-580, \\ São Luís, MA, \\ ${ }^{2}$ Universidade Federal do Maranhão, Departamento de Química, Av. Portugueses, 1966, 65085-580, São Luís, MA, \\ e-mail: elisiofisico@gmail.come-mail:apm.ufma@gmail.com
}

\begin{abstract}
RESUMO
Lamas geradas em decantadores de Estação de Tratamento de Água (ETA) têm sido incorporadas em argilas, principalmente para fabricação de cerâmica vermelha. Neste trabalho foi utilizado lodo da ETA do Sacavém, São Luís-MA e argila vermelha de Imperatriz-MA. A metodologia consistiu de ensaios de caracterização do lodo seco e da argila seca por Difração de Raios X, Fluorescência de Raios X, Microscopia Eletrônica de Varredura, Análise Térmica Diferencial e Termogravimétrica. Foram incorporados 5, 10, 15, 20 e 25\% da massa do lodo na massa argilosa. Foram confeccionados 48 corpos de prova por prensagem uniaxial a $40 \mathrm{MPa}$ e tratados a $950^{\circ} \mathrm{C}$ por 3 horas. Foram determinadas as propriedades físicas e mecânicas dos corpos por meio dos seguintes ensaios: Retração Linear de Queima, Absorção de Água, Tensão de Ruptura à Flexão, Porosidade Aparente, Perda ao Fogo e Massa Específica Aparente. Foi observado pela análise química de Fluorescência de Raios $\mathrm{X}$ que os componentes predominantes em forma de óxidos $\mathrm{SiO}_{2}, \mathrm{Al}_{2} \mathrm{O}_{3}$ e $\mathrm{Fe}_{2} \mathrm{O}_{3}$ correspondem a aproximadamente $91 \%$ da composição do lodo e $89,2 \%$ da composição da argila, o que pode ter propiciado resultados positivos no processamento das misturas do lodo e argila e nas propriedades físico-mecânicas dos corpos de prova. Os resultados demonstraram que os valores de absorção de água variaram de acordo com os teores do lodo de ETA aplicados na argila e que todos os corpos de prova apresentaram valores de absorção de água inferiores a $25 \%$, máximo permitido para produção de blocos cerâmicos. Verificou-se que os corpos de prova com a adição de até $15 \%$ de lodo na argila podem ser usados para fabricação de tijolos maciços.
\end{abstract}

Palavras-chave: resíduos sólidos, cerâmica vermelha, reciclagem.

\section{INTRODUÇÃO}

Necessidades básicas, tais como higiene, exercícios físicos, diversão, saúde e alimentação dependem essencialmente de água doce. Mesmo que haja uma capacidade de renovação da água doce disponível para consumo - por volta de $2,5 \%$ do volume total de água do planeta - mediante processos naturais, sua reposição tem sido comprometida por fatores antropogênicos (desmatamentos, exploração, poluição de mananciais, etc.). Com o passar dos anos, a água fica mais escassa e ameaçada pela ineficiência de uso e desperdícios.

Água potável é obtida na maioria das empresas de saneamento utilizando-se o processo convencional de tratar água em Estação de Tratamento de Água (ETA). As principais fases deste processo são: coagulação, floculação, sedimentação, filtração e desinfecção. Nesses processos são usados filtros e vários produtos químicos, conforme normas vigentes, para retirada de impurezas e microrganismos nocivos. Porém, gera-se como resíduo o lodo de Estação de Tratamento de Água ou lodo de ETA (LETA). Esse resíduo do tratamento da água é formado por sólidos, aglomerados orgânicos e inorgânicos, resultantes de reações entre os produtos químicos e as impurezas contidas na água [1].
A maior parte das massas dos lodos em ETAs convencionais é acumulada nos decantadores e as outras parcelas de resíduos são oriundas de limpezas de filtros. No Brasil, grande parte dessas ETAs destinam seu lodo diretamente em mananciais mais próximos, não fornecendo destinação adequada para esse tipo de resíduo [2].

O LETA é classificado pela NBR 10004 [3] como um resíduo sólido, não sendo permitido seu lançamento em águas superficiais. Resíduos industriais sólidos não devem ser lançados na rede de esgotos ou nos corpos hídricos. O manejo e tratamento desses resíduos são responsabilidades de quem os gerou [4] e deve estar em conformidade com as normas da Política Nacional de Resíduos Sólidos (PNRS) [5].

As ETAs utilizam coagulantes inorgânicos constituídos em sua maioria de sais de ferro e alumínio [6]. O alumínio, contido no lodo da ETA, possui característica acumulativa e se descartado incorretamente, pode impactar negativamente o meio [7]. Segundo o IBGE, comumente os resíduos de tratamento de água são dispostos diretamente e sem tratamento adequado nos recursos hídricos [8] e o lançamento de lodos de ETAs em ambientes aquáticos pode causar danos à sua fauna, por isso essa ação pode ser considerada um crime ambiental [9]. 
Resíduos industriais, gerados em enormes quantidades no Brasil e no mundo, têm sido motivo de estudo por parte das indústrias e de centros de pesquisas na busca de soluções, que sejam ecologicamente corretas, viáveis e capazes de diminuir os impactos ambientais decorrentes da disposição desses resíduos no meio ambiente.

O programa de ação consensual, intitulado "Agenda 21 da Conferência das Nações Unidas sobre Meio Ambiente e Desenvolvimento", centra-se também em áreas de programas relacionadas a incentivo sobre pesquisas de controle de poluição por parte de órgãos governamentais, municipais e autoridades locais, bem como o tratamento, redução, reutilização e reciclagem ambientalmente saudáveis de resíduos sólidos [10].

Devido aos impactos ambientais decorrentes dessas ações, têm-se buscado alternativas de disposição, aproveitamento e uso benéfico desse resíduo. Uma alternativa interessante para a reciclagem desse resíduo e uma possível solução para destinação ambientalmente correta é a incorporação do lodo na cerâmica vermelha. Isso é possível em função de sua composição química, física e mineralógica ser muito semelhante à das argilas. Essa alternativa pode contribuir positivamente com a conservação dos mananciais. Além disso, pode reduzir o consumo das argilas, aumentando a vida útil de aterros sanitários e para a melhoria da qualidade do solo [11].

Neste contexto, foi estudada uma alternativa ambientalmente correta para a destinação dos lodos de ETAs, por meio da sua utilização como carga em argila para produção de cerâmicas vermelhas e da avaliação de qualidade, por meio de requisitos técnicos das peças obtidas.

\section{MATERIAIS E MÉTODOS}

As amostras de argila e lodo foram cedidas pelo Laboratório de Processamento Cerâmico do Instituto Federal de Educação, Ciência e Tecnologia do Maranhão - IFMA, secas e acondicionadas em sacos de polietileno.

A argila bruta foi coletada no município de Imperatriz, no estado do Maranhão. O lodo bruto foi oriundo da ETA do Sacavém, em São Luís-MA, e também acondicionado em sacos de polietileno. A ETA do Sacavém é do tipo convencional, onde são realizadas as etapas de coagulação, floculação, decantação, filtração, desinfecção, correção do $\mathrm{pH}$ e fluoretação.

Para a realização das caracterizações das amostras em pó do lodo e da argila, as mesmas foram peneiradas, separadamente, em 60 mesh e depois passaram pelo processo de secagem em estufa a $70^{\circ} \mathrm{C}$ por $24 \mathrm{~h}$.

A determinação qualitativa de estruturas cristalinas das amostras do lodo e da argila foi realizada em um difratômetro de Raios-X Bruker, modelo D8 Advance, utilizando radiação monocromática de $\mathrm{Cu}$, tensão de $40 \mathrm{kV}$, corrente de $20 \mathrm{~mA}$, varredura com passo de $0,02^{\circ}$, detector linear, razão de contagem por passo de $1 \mathrm{~s}$ e calibrado em $2 \theta$ com padrão de silício. As fases cristalinas presentes no difratograma foram identificadas pela comparação com padrões difratométricos de minerais do banco de dados do International Center for Diffraction Data - ICDD e os resultados obtidos foram analisados por meio do software Xpert High Score Plus com base de dados JCPDS (Joint Committee on Powder Diffraction Standards).

As micrografias eletrônicas dos pós de lodo e de argila foram obtidas em um equipamento MEV. O microscópio utilizado foi um modelo da FEI Inspect F50 com canhão Schottky Field Emission Gun (FEG), num porta-amostra com redução de carga.

A análise térmica do pó do lodo foi realizada num equipamento Analisador térmico simultâneo TG/DTA SHIMADZU, modelo STA-409, sob fluxo de nitrogênio, entre $29^{\circ} \mathrm{C}$ e $1350^{\circ} \mathrm{C}$ com uma taxa de aquecimento de $15^{\circ} \mathrm{C}$ por minuto.

Os constituintes elementares das amostras de lodo e da argila foram determinados em um equipamento Espectrofotômetro de Fluorescência de Raios X por Dispersão de Comprimento de Onda (WDXRF) da Bruker, com as seguintes especificações: modelo S8 Tiger, com fonte de radiação de Ródio $(\mathrm{Rh})$, potência de $30 \mathrm{kV}$, corrente de 33mA, colimador 0,23 graus, cristal XS-55, detector selado, LLD 1,0 ppm, filmes $\operatorname{Myler}^{\circledR}(3,6 \mu \mathrm{m})$, recipientes de teflon e diâmetro da máscara $34 \mathrm{~mm}$.

Foram confeccionados corpos de prova com argila pura e com 5, 10, 15, 20 e 25\% de LETA. Após a compactação e depois de codificados, enumerados, medidos suas massas verdes em balança analítica e suas dimensões por meio de um paquímetro digital e tabelados esses dados, os corpos de prova foram levados à secagem em estufa ventilada a $110^{\circ} \mathrm{C}$ por 24 horas.

Foram medidas as massas secas dos corpos de prova em balança analítica e suas dimensões com um paquímetro digital.

O Processo de Queima dos corpos de prova foi realizado em forno elétrico em atmosfera oxidante até $950^{\circ} \mathrm{C}$. A taxa de aquecimento programada para a primeira etapa foi de $2^{\circ} \mathrm{C} / \mathrm{min}$, até um patamar de $110^{\circ} \mathrm{C}$ por 1 hora. Na segunda etapa, $5^{\circ} \mathrm{C} / \mathrm{min}$ e patamar de $550^{\circ} \mathrm{C}$ por 1 hora. Após este patamar, manteve-se a taxa de aquecimento em $5^{\circ} \mathrm{C} / \mathrm{min}$ até $950^{\circ} \mathrm{C}$ por 3 horas. O resfriamento dos corpos de prova ocorreu por convecção natural. Após o tratamento térmico, os corpos de prova foram acondicionados em dessecador com sílica gel. Posteriormente, foram novamente medidas suas massas e dimensões.

Após o processo de queima, foram investigadas as seguintes propriedades tecnológicas: Retração Linear de Queima (RLQ), Tensão de Ruptura à Flexão (TRF), Absorção de Água, Porosidade Aparente, Massa Específica Aparente (MEA) e Perda ao Fogo.

\section{RESULTADOS}

As análises químicas quantitativas de Fluorescência de raios X por Dispersão de Comprimento de Onda da argila e do lodo podem ser verificadas e comparadas na Tabela 1. Observa-se que as matérias primas são constituídas predominantemente por $\mathrm{SiO}_{2}, \mathrm{Al}_{2} \mathrm{O}_{3}, \mathrm{Fe}_{2} \mathrm{O}_{3}$, $\mathrm{K}_{2} \mathrm{O}$ e $\mathrm{TiO}_{2}$ e em menores concentrações por $\mathrm{MgO}, \mathrm{BaO}$, $\mathrm{P}_{2} \mathrm{O}_{5}$ e $\mathrm{CaO}$ para a argila e em menores concentrações por $\mathrm{MgO}, \mathrm{SO}_{3}, \mathrm{P}_{2} \mathrm{O}_{5}, \mathrm{CaO}$ para o lodo. 
Tabela 1: Óxidos dos elementos químicos da argila e do lodo detectados por WDXRF.

\begin{tabular}{ccc}
\hline $\begin{array}{c}\text { ÓXIDOS } \\
\text { PRESENTES }\end{array}$ & $\begin{array}{c}\text { ARGILA } \\
(\%)\end{array}$ & $\begin{array}{c}\text { LODO } \\
\mathbf{( \% )}\end{array}$ \\
\hline $\mathrm{SiO}_{2}$ & 58,33 & 52,19 \\
$\mathrm{Al}_{2} \mathrm{O}_{3}$ & 15,96 & 17,70 \\
$\mathrm{Fe}_{2} \mathrm{O}_{3}$ & 14,98 & 21,09 \\
$\mathrm{~K}_{2} \mathrm{O}$ & 5,57 & 4,08 \\
$\mathrm{TiO}_{2}$ & 2,02 & 2,03 \\
\hline $\mathrm{MgO}$ & 0,70 & 0,54 \\
\hline $\mathrm{SO}$ & - & 0,45 \\
\hline $\mathrm{BaO}$ & 0,65 & - \\
\hline $\mathrm{P}_{2} \mathrm{O}_{5}$ & 0,49 & 0,78 \\
\hline $\mathrm{CaO}$ & 0,44 & 0,31 \\
\hline
\end{tabular}

O difratograma do lodo de ETA, mostrado na Figura 1, nos permitiu identificar as fases cristalinas constituintes dos seguintes minerais: Quartzo $\left(\mathrm{SiO}_{2}\right)$, Caulinita $\left(\mathrm{Al}_{2} \mathrm{Si}_{2} \mathrm{O}_{5}(\mathrm{OH})_{4}\right)$, Muscovita $\left(\mathrm{KAl}_{2}\left(\mathrm{Si}_{3} \mathrm{Al}\right) \mathrm{O}_{10}(\mathrm{OH}, \mathrm{F})_{2}\right)$ e Nacrita $\left(\mathrm{Al}_{2} \mathrm{Si}_{2} \mathrm{O}_{5}(\mathrm{OH})_{4}\right)$, que apresenta a mesma unidade estrutural da Caulinita. Estes resultados concordam com as análises químicas feitas por WDXRF: a fase majoritária do Quartzo é devida a presença do óxido de silício, cuja concentração na amostra do lodo é majoritária, chegando a $52,19 \%$.

O difratograma da argila, ilustrado na Figura 2, nos permitiu identificar as mesmas fases encontradas no lodo, com exceção da Microlina, que é um mineral do grupo dos feldspatos potássicos, cuja composição química é dada pela fórmula $\mathrm{KAlSi}_{3} \mathrm{O}_{8}$. Sua presença pode ser confirmada pela existência do óxido de potássio, de sílica e alumínio, como mostrado na análise de WDXRF.

A Figura 3 ilustra as curvas da análise termogravimétrica do lodo. As curvas indicam que para o resíduo lodo são identificados três eventos associados à perda de massa durante o aquecimento no intervalo de $29^{\circ} \mathrm{C}$ a $1350^{\circ} \mathrm{C}$. Observa-se uma perda de massa de aproximadamente $4,33 \%$, devido à eliminação de água, que ocorre até aproximadamente a $200^{\circ} \mathrm{C}$. Entre $200^{\circ} \mathrm{C}$ e $800^{\circ} \mathrm{C}$ existe perda de massa associada à decomposição da matéria orgânica, aproximadamente $11,08 \%$. Por último, entre $800^{\circ} \mathrm{C}$ e $1350^{\circ} \mathrm{C}$ há uma perda de massa devido à decomposição de argilominerais de 2,83\%. Ao todo a análise térmica mostrou uma perda de massa equivalente a $18,24 \%$.

A Figura 4 apresenta características morfológicas típicas dos grãos do lodo de ETA. A micrografia mostrada na Figura 4 (A) apresenta uma ampliação de 4000 vezes da amostra de lodo. Nesta micrografia podem ser observadas partículas com diâmetros de poucos micrometros aderidas as faces de grãos maiores com diâmetros de dezenas de micrometros. Esse comportamento é característico para amostras de lodo, dado a existência de material orgânico e inorgânico. Sendo assim, o lodo apresenta-se heterogêneo, como pode ser constatado na Figura 4 (B).

$\mathrm{Na}$ Figura 5 têm-se as micrografias da argila pura. A Figura 5 (A), com aumento de 2000 vezes, mostra que na argila existem grãos aglomerados formados por

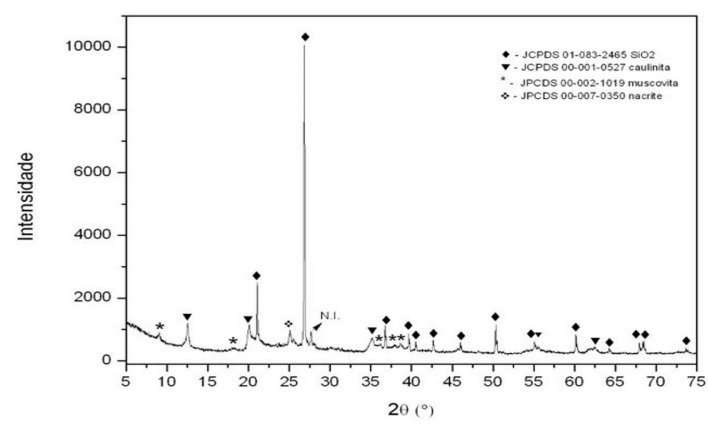

Figura 1: Difratograma de raios $\mathrm{X}$ do lodo.

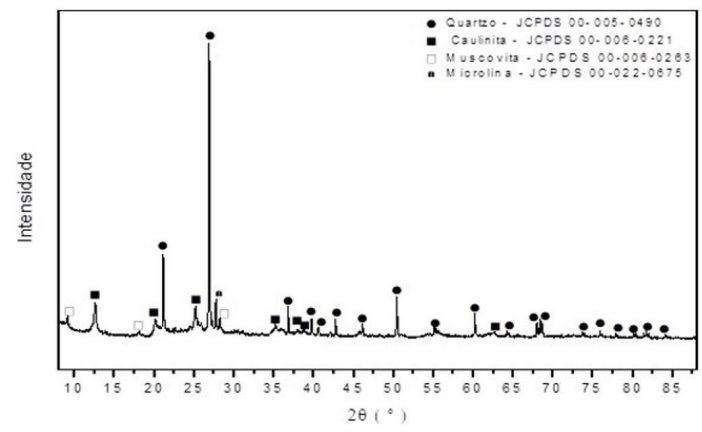

Figura 2: Difratograma de raios $\mathrm{X}$ da argila.

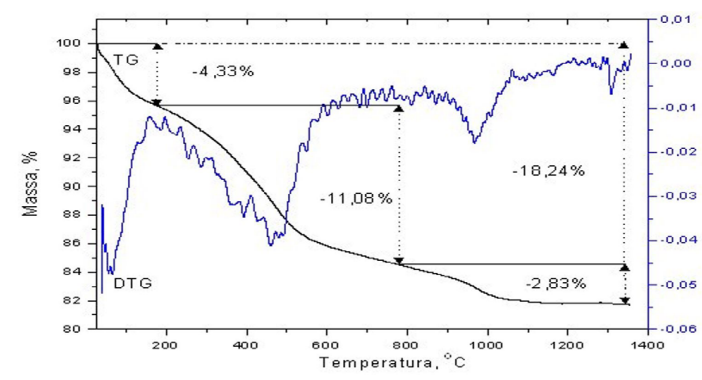

Figura 3: TG e DTG do lodo de ETA.

partículas menores. Na Figura 5 (B), observa-se que as partículas menores são compostas por grãos de formas variadas. Esse comportamento está de acordo com os resultados de difração de raios $\mathrm{X}$, no qual foi observada a existência de várias fases cristalinas.

Foram confeccionados 48 corpos de prova. Após os mesmos serem tratados termicamente até $950^{\circ} \mathrm{C}$, em forno mufla por 24 horas, foram submetidos aos ensaios de Retração Linear de Queima (RLQ), Perda ao Fogo e Tensão de Ruptura à Flexão (TRF). Para efeitos estatísticos qualitativos, esses ensaios tecnológicos foram feitos em 24 corpos de prova, sendo 4 corpos sem adição de lodo $(0 \%)$ e 20 corpos com 5, 10, 15, 20 e $25 \%$ de lodo, distribuídos 4 corpos para cada porcentagem de mistura.

Os resultados obtidos de RLQ, Figura 6, indicaram que a adição de lodo de 5 a $20 \%$ na massa argilosa causou uma diminuição na retração linear nos corpos de prova, variando entre $-0,3 \%$ e $-0,11 \%$. Observou-se uma 

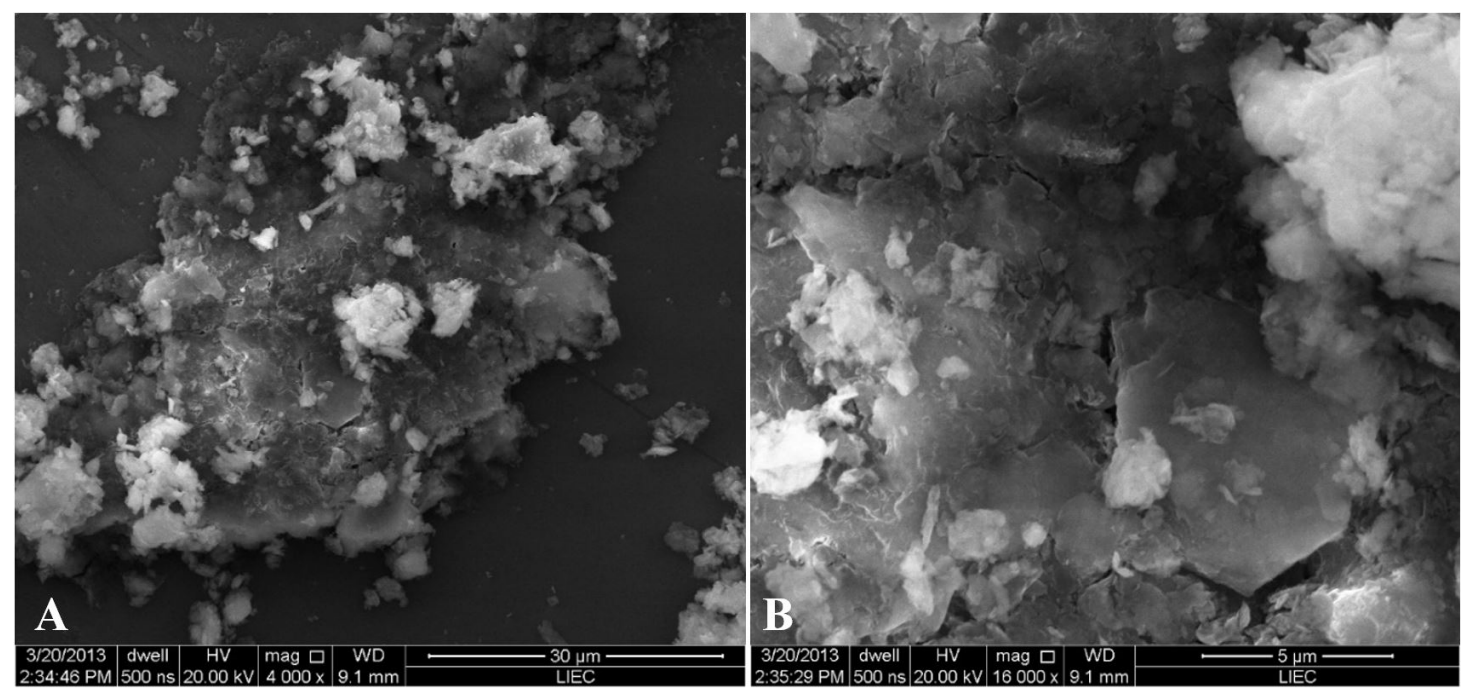

Figura 4: Micrografias obtidas por MEV de LETA.
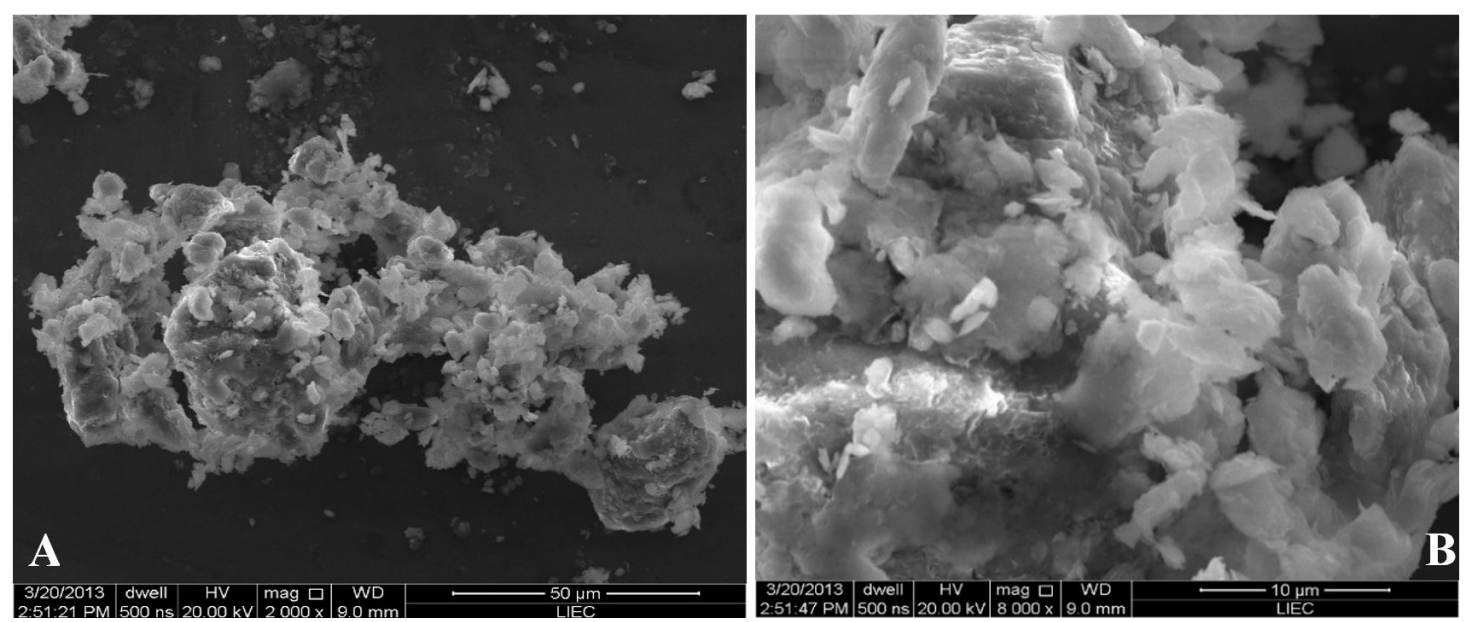

Figura 5: Micrografias obtidas por MEV da argila.

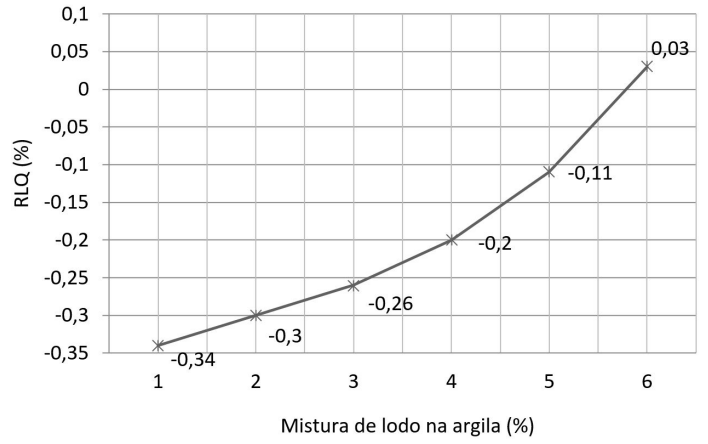

Figura 6: RLQ em função da porcentagem de LETA adicionado na massa argilosa.

expansão de $0,03 \%$, oriunda da adição de $25 \%$ de lodo na massa argilosa.

A média dos valores de Perda ao Fogo foi determinada para 4 corpos de prova sem adição de lodo $(0 \%)$ e seguiu o mesmo procedimento utilizado para a RLQ, conforme a
Figura 7. Observou-se na Figura 7 que a perda de massa dos corpos aumentou, respectivamente, de 4,86\% para $6,29 \%$, partindo da argila pura até a argila misturada com $25 \%$ de lodo.

Os ensaios realizados nos 24 corpos de prova estão descritos na Tabela 2 .

A Figura 8 mostra os valores médios encontrados, em MPa, nos ensaios de Tensão de Ruptura à Flexão (TRF) dos corpos de prova confeccionados com e sem adição de lodo.

Pelo resultado mostrado na Figura 8, quanto maior é a porcentagem de lodo na argila menor é o valor da Tensão de Ruptura à Flexão.

Os ensaios realizados nos 24 corpos de prova estão descritos na Tabela 3 .

A Figura 9 apresenta os valores médios encontrados, em porcentagem, nos ensaios de Absorção de Água dos corpos constituídos com lodo e corpos sem lodo.

A Figura 10 mostra os valores médios encontrados, em porcentagem, nos ensaios de Porosidade Aparente 
Tabela 2: Ensaios tecnológicos de TRF realizados em 24 corpos de prova.

\begin{tabular}{|c|c|c|c|c|c|c|}
\hline \multicolumn{6}{|c|}{ ENSAIO TECNOLÓGICO DE TRF } & \\
\hline $\begin{array}{c}\text { ARGILA } \\
\text { PURA }\end{array}$ & $5 \%$ LODO & $10 \%$ LODO & $15 \%$ LODO & $20 \%$ LODO & $25 \%$ LODO & \\
\hline & $1 \mathrm{~A}$ & $1 \mathrm{LA} 5 \%$ & 1LA10\% & 1LA15\% & 2LA20\% & $1 \mathrm{LA} 25 \%$ \\
\hline & $2 \mathrm{~A}$ & 2LA5\% & 2LA $10 \%$ & 2LA15\% & $3 \mathrm{LA} 20 \%$ & $2 \mathrm{LA} 25 \%$ \\
\hline & $3 \mathrm{~A}$ & $3 \mathrm{LA} 5 \%$ & 3LA $10 \%$ & 3LA15\% & 4LA20\% & $3 \mathrm{LA} 25 \%$ \\
\hline & $4 \mathrm{~A}$ & $4 \mathrm{LA} 5 \%$ & 4LA10\% & 4LA $15 \%$ & $5 \mathrm{LA} 20 \%$ & $4 \mathrm{LA} 25 \%$ \\
\hline
\end{tabular}

Tabela 3: Ensaios tecnológicos de AA, MEA, PA realizados em 24 corpos de prova.

\begin{tabular}{|c|c|c|c|c|c|c|}
\hline \multicolumn{6}{|c|}{ ENSAIOS TECNOLÓGICOS DE AA, MEA E PA } & \\
\hline $\begin{array}{l}\text { ARGILA } \\
\text { PURA }\end{array}$ & $5 \%$ LODO & $10 \%$ LODO & $15 \%$ LODO & $20 \%$ LODO & $25 \%$ LODO & \\
\hline & $5 \mathrm{~A}$ & $6 \mathrm{LA} 5 \%$ & 7LA $10 \%$ & $8 \mathrm{LA} 15 \%$ & 7LA20\% & $6 \mathrm{LA} 25 \%$ \\
\hline & $6 \mathrm{~A}$ & 7LA5\% & $8 \mathrm{LA} 10 \%$ & 9LA $15 \%$ & $8 \mathrm{LA} 20 \%$ & 7LA25\% \\
\hline & $7 \mathrm{~A}$ & $8 \mathrm{LA} 5 \%$ & 9LA $10 \%$ & 10LA15\% & 9LA $20 \%$ & $8 \mathrm{LA} 25 \%$ \\
\hline & $8 \mathrm{~A}$ & 9LA5\% & $10 \mathrm{LA} 10 \%$ & $11 \mathrm{LA} 15 \%$ & $10 \mathrm{LA} 20 \%$ & 9LA25\% \\
\hline
\end{tabular}

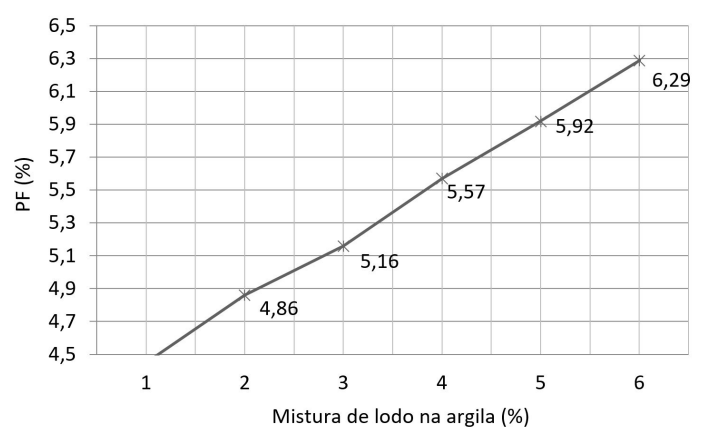

Figura 7: Perda ao fogo em função da adição de lodo na mistura de argila.

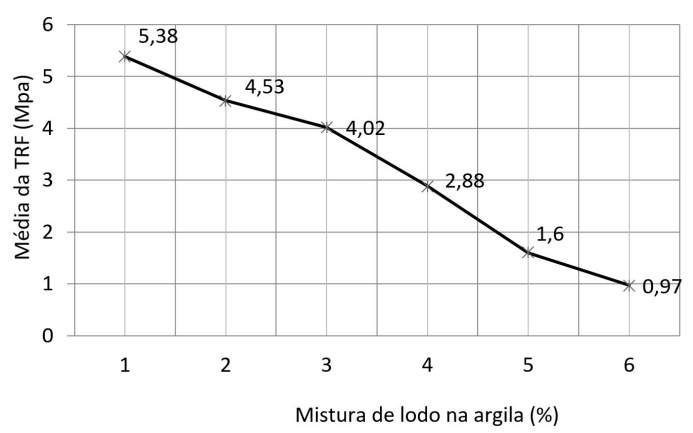

Figura 8: Variação da TRF em função da percentagem de lodo na argila.

dos corpos de prova, confeccionados com e sem adição de lodo.

Os resultados sugerem que a Porosidade Aparente obteve maiores percentuais nos corpos constituídos com $25 \%$ de lodo e menores percentuais nos corpos com ausência de lodo. Os resultados indicaram uma relação

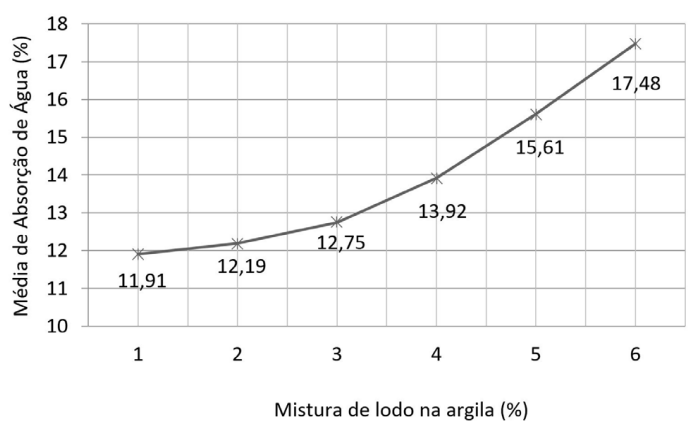

Figura 9: Absorção de Água em função da porcentagem de lodo na argila.

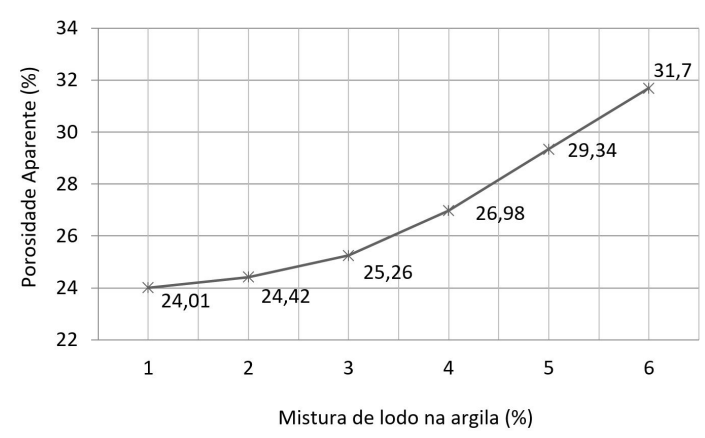

Figura10: Porosidade Aparente em flunção da porcentagem de lodo na argila.

diretamente proporcional entre a Absorção de água e Porosidade Aparente.

Os resultados do ensaio da Massa Específica Aparente, Figura 11, indicaram uma relação inversamente proporcional entre a densidade aparente dos corpos e adição do lodo na massa argilosa. 


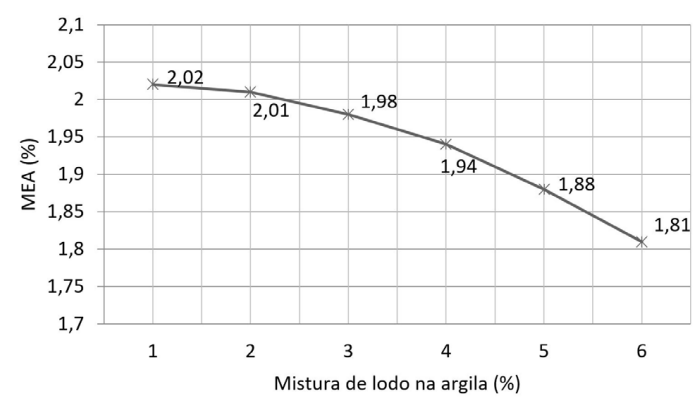

Figura 11: Massa Específica Aparente em função da adição de lodo na mistura de argila.

\section{DISCUSSÃO}

Os óxidos $\mathrm{SiO}_{2}$ (Óxido de silício), $\mathrm{Al}_{2} \mathrm{O}_{3}$ (Óxido de alumínio) e $\mathrm{Fe}_{2} \mathrm{O}_{3}$ (Óxido de ferro), corresponde a aproximadamente $91 \%$ da composição do lodo e $89,2 \%$ da composição da argila. Esses são os principais óxidos presentes em lodos de ETAs estudados que constam em alguns trabalhos abordados na literatura [11,12]. Sendo assim, a adição do lodo na argila contribui para diminuir a resistência das peças, pois nele existe uma menor concentração de óxido de silício em relação à argila. Por outro lado, o lodo possui um maior percentual de óxido de titânio que pode contribuir na resistência dos corpos de prova.

Na massa cerâmica as substâncias $\mathrm{CaO}$ e $\mathrm{MgO}$ atuam como agentes fundentes com a capacidade de diminuir a temperatura de formação de fase líquida durante o processo de queima. Tendem a baixar a refratariedade de argilas. Geralmente, são provenientes de calcita, dolomita, gipsita e são raramente encontrados em argilas cauliníticas do tipo refratário [13].

$\mathrm{O}$ teor de $\mathrm{Al}_{2} \mathrm{O}_{3}$ na composição química do lodo, detectado por WDXR, pode estar relacionado com a presença de hidróxido de alumínio $\left(\mathrm{Al}(\mathrm{OH})_{3}\right)$, oriundo tanto da reação do coagulante utilizado no processo de tratamento de água da ETA, o sulfato de alumínio, quanto da caulinita presente no lodo [11].

O baixo teor de calcário é vantajoso, pois, argilas com alto teor de calcário tendem a apresentar maior porosidade e menor resistência mecânica após a queima [14].

Foram observadas nas micrografias do lodo de ETA, apresentadas na Figura 4, morfologias típicas de partículas de lodo de ETA [15]. Observa-se perfis estruturados e irregulares de aglomerações evidenciando a existência de material orgânico unido às faces das partículas. Os aglomerados de partículas possuem aparência porosa, tamanhos variados, sem formas definidas, formatos e perfis padronizados. Observa-se aglomeração de partículas lamelares nas microrregiões com distintos tamanhos. As micrografias apresentam detalhes da topografia com perfil irregular com as superfícies dos grânulos em formato de placas lamelares.

Nas micrografias dos grãos de argila, ilustradas na Figura 5, observa-se diferentes formas e diâmetros de partículas, aglomerados de bordas irregulares e formas arredondadas, resultante da aglomeração de partículas de morfologia pseudo-hexagonal, e também apresentam formato laminar característicos dos cristais de caulinita. Nota-se também a presença de monocristais arredondados coexistindo com as lamelas de caulinita.

A fase da Caulinita pode estar relacionada com os componentes expressos pelo óxido de silício e de alumínio, cuja concentração chegou a $69,89 \%$. A presença da fase Muscovita está associada com pequenas concentrações de óxido de potássio com filossilicatos na amostra. Enquanto que a fase da Nacrita, deve-se a presença de silicato argiloso de alumínio, que ocorre com a Caulinita. O componente expresso pelo óxido de ferro, cuja concentração chega a $21,09 \%$ não foi identificado como fase cristalina.

A expansão de $0,03 \%$, oriunda da adição de lodo na massa cerâmica de $25 \%$, pode estar relacionado com a constituição predominante de $\mathrm{SiO}_{2}$ no lodo e na argila. De acordo com SANTOS [16], geralmente, as argilas devem apresentar mínima retração durante a secagem, porém, alguns materiais apresentam uma pequena expansão, pois devido à retirada da peça do molde, onde estava comprimida, a mesma fica livre de tensões e aumenta de tamanho e isso ocorre frequentemente com materiais que possuem elevado teor de quartzo e são moldados com baixa umidade.

Assim, levando em consideração esse ensaio, a adição de 5 e $10 \%$ de lodo na mistura, pode ser adequada para a utilização na massa cerâmica, dado que a expansão nessas peças pode ser considerada insignificante.

As matérias primas, lodo e argila, analisadas de acordo as técnicas de XRF e WDXRF são constituídas predominantemente por componentes que expressam o $\mathrm{SiO}_{2}$. Portanto, devido ao $\mathrm{SiO}_{2}$ ter um elevado ponto de fusão, ser um componente refratário e expresso majoritariamente nas matérias primas analisadas, provavelmente, ele foi um fator que contribuiu para a expansão linear dos corpos de prova. Assim, pode ter acontecido uma menor qualidade na mistura com o incremento da incorporação do lodo na argila.

De acordo com a NBR 7170 [17], a resistência mínima à compressão em tijolos comuns maciços para a categoria A é 1,5 Mpa, para a categoria B é 2,5 Mpa e para a categoria Cé 4,0. De acordo com SANTOS [16] para que uma massa cerâmica possa ser usada para a fabricação de tijolos e telhas, os valores-limites da Tensão de Ruptura da massa após a queima são os seguintes:

- Para tijolos de alvenaria equivale a $20 \mathrm{kgf} / \mathrm{cm}^{2}$ (2 Mpa);

- Para tijolos furados equivale a $55 \mathrm{kgf} / \mathrm{cm}^{2}(5,5 \mathrm{Mpa})$;

- Para telhas equivale a $65 \mathrm{kgf} / \mathrm{cm}^{2}(6,5 \mathrm{Mpa})$.

Os resultados mostram que a massa argilosa, misturada com lodo a $20 \%$, é adequada para a fabricação de tijolos maciços de categoria A. A massa argilosa, misturada com lodo de 5 a $15 \%$, é adequada para a fabricação de tijolos maciços de categorias B. A massa argilosa, misturada 
com lodo de 5 a $10 \%$, é adequada para a fabricação de tijolos maciços de categorias C. A massa argilosa pura é adequada para a fabricação de tijolos maciços, porém, é inadequada para fabricação de telhas e se aproximou para os valores padrões para fabricação de blocos perfurados.

Como o ensaio de TRF objetivou medir a resistência mecânica do produto final, quando o mesmo foi submetido a forças perpendiculares sobre suas faces, na prática, é fundamental que esse produto possua uma boa resistência com relação à pressão exercida pelo peso, por exemplo, de uma parede sobre o mesmo. Portanto, é importante o atender aos critérios das normas vigentes a fim de evitar rachaduras em paredes e outros desastres nos setores da construção civil.

Foi observado que todos os valores do ensaio de TRF foram diminuindo de acordo com a quantidade de lodo adicionado na argila, como é mostrado na Figura 6. Provavelmente, esse fato pode estar relacionado ao aumento da porosidade do material devido à perda ao fogo que aumentou com a adição de lodo na massa cerâmica.

Com o aumento da temperatura de queima os valores da TRF podem aumentar, visto que há um aumento na densificação dos corpos e, consequentemente, a redução da porosidade dos corpos de prova. Segundo TARTARI [18], a PA considera apenas os poros abertos que absorvem água e é um método preponderante para avaliação dos materiais cerâmicos que deve ser confrontado diretamente com os resultados da Massa Específica Aparente e Absorção de água, de forma a avaliar a influência térmica com o grau de sinterização dos corpos de prova, em função de propriedades físico-mecânicas.

Verificou-se que todas as amostras tratadas a temperatura de $950^{\circ} \mathrm{C}$ não ultrapassaram os valores de Absorção de Água recomendados pela NBR 15270-1 [19] que, para blocos cerâmicos e para alvenaria de vedação são de no mínimo $8 \%$ e no máximo $22 \%$.

De acordo com SANTOS [16], para a utilização da massa na produção de blocos cerâmicos, após a Queima, a Porosidade Aparente deve estar em torno de 4\% até 35\%.

As curvas da análise termogravimétrica do lodo indicaram três eventos associados à perda de massa durante o aquecimento no intervalo de $29^{\circ} \mathrm{C}$ a $1350^{\circ} \mathrm{C}$ : perda de massa devido à eliminação de água adsorvida a sua superfície, de massa associada à decomposição da matéria orgânica e da decomposição de argilominerais. Ao todo a análise térmica mostrou uma perda de massa equivalente a $18,24 \%$. À medida que os corpos de prova foram recebendo energia térmica no processo de queima, suas massas específicas aumentaram e, consequentemente, suas porosidades diminuíram e suas resistências mecânicas aumentaram. De acordo com SANTOS [16], para se utilizar uma massa argilosa em cerâmica vermelha os valores do ensaio de MEA, após a Queima, devem estar entre 1,7 e $2,1 \mathrm{~g} / \mathrm{cm} 3$, conforme mostra a Figura 10. Portanto, todas as composições atenderam a esse requisito.

A perda ao fogo das peças pode estar associada à presença de elementos que se volatilizaram durante o processo de queima, tais como: hidroxilas de argilominerais, hidróxidos, componentes de matéria orgânica e outros elementos. Segundo SANTOS [16], para um bloco cerâmico a perda ao fogo não deve ultrapassar a $15 \%$.

Todos resultados obtidos nos ensaios estão de acordo com os referenciados pela $\mathrm{ABNT}$, no que diz respeito à Perda ao Fogo com percentual inferior a 10\%, à Retração Linear com percentual inferior a 6\%, à Absorção de Água com percentual inferior a $20 \%$, à Tensão de Ruptura à Flexão com percentual superior a $2 \mathrm{MPa}$ e à Massa Específica Aparente com percentual superior a $1,7 \mathrm{~g} / \mathrm{cm}^{3}$.

\section{CONCLUSÕES}

O lodo apresenta as fases cristalinas: Quartzo, Caulinita, Muscovita e Nacrita. A argila também apresenta as mesmas fases do lodo, com exceção da Microlina. Estes resultados concordam com as análises químicas das matérias primas e nos permitem dizer que podem ser usadas como componente em cerâmica vermelha.

Algumas peças cerâmicas confeccionadas obedecem aos requisitos técnicos de qualidade. Os valores dos ensaios de TRF permitiram observar que a adição de lodo na argila não fere os padrões especificados para fabricação de cerâmica vermelha.

Os ensaios de Absorção de Água dos corpos de prova, confeccionados com adição de lodo e dos corpos sem adição de lodo, não ultrapassaram aos valores de absorção de água recomendados. A perda de massa teórica nas peças cerâmicas, na temperatura de $950^{\circ} \mathrm{C}$, cumpriu a exigência para corpos cerâmicos.

Portanto, os resultados do ensaio de TRF mostraram que algumas peças cerâmicas obtidas são propícias para serem usadas em cerâmicas vermelhas. Os valores dos ensaios de TRF mostraram que a adição de até $15 \%$ de lodo na argila obedece aos padrões especificados para fabricação de tijolos maciços, sendo viável a utilização de lodo de ETA como carga na argila para a produção de cerâmicas vermelhas associadas à sustentabilidade desse recurso mineral não renovável.

Assim, pelo fato da argila ser um recurso natural não renovável e de acordo com o estudo de suas propriedades mecânicas pelos ensaios tecnológicos, os resultados demonstraram que a mesma pode ser substituída, mesmo em pequenas quantidades, pelo resíduo lodo, podendo viabilizar o processo de construção civil e minimizar a perda desse valioso recurso natural.

\section{AGRADECIMENTOS}

Agradecemos à Universidade Federal do Maranhão (UFMA), ao Programa de Pós-Graduação em Energia e Ambiente da Universidade Federal do Maranhão (PPGEA) e ao Instituto Federal de Educação, Ciência e Tecnologia do Maranhão - IFMA pela cessão dos laboratórios, materiais e ferramentas, elementos essenciais à realização deste estudo.

\section{BIBLIOGRAFIA}

[1] FERREIRA FILHO, S.S., Tratamento de água: Concepção, projeto e operação de estações de tratamento, 1 ed., Rio de Janeiro, Elsevier Editora Ltda., 2017. 
[2] ACHON, C. L., BARRoso, M. M., CORDEIRO, J. S., "Resíduos de estações de tratamento de água e a ISO 24512: desafio do saneamento brasileiro", Engenharia Sanitária e Ambiental, v.18, n.2, pp. 115-122, abr./jun. 2013.

[3] ASSOCIAÇÃO BRASILEIRA DE NORMAS TÉCNICAS. NBR 10004: Resíduos sólidos - Classificação, Rio de Janeiro, 2004.

[4] BRASIL. Lei ${ }^{\circ} 9433$, de 08 de janeiro de 1997. Institui a Política Nacional de Recursos Hídricos, cria o Sistema Nacional de Gerenciamento de Recursos Hídricos. Diário Oficial da União, Brasília, DF, 09 jan. 1997.

[5] BRASIL. Lei ${ }^{\circ} 12305$, de 02 de agosto de 2010. Institui a Política Nacional de Resíduos Sólidos; altera a Lei nº 9.605, de 12 de fevereiro de 1998; e dá outras providências. Diário Oficial da União, Brasília, DF, 03 ago. 2010.

[6] CORAL, L. A., BERGAMASCO R., BASSETTI F. J., Estudo da viabilidade de utilização do polímero natural (TANFLOC) em substituição ao sulfato de alumínio no tratamento de águas para consumo, In: $2^{\text {nd }}$ International Workshop Advances in Cleaner Production, 20-22 mai., 2009, São Paulo.

[7] SKORONSKI, E., et al., "Estudo da aplicação de tanino no tratamento de água para abastecimento captada no rio Tubarão, na cidade de Tubarão, SC", Taubaté, Revista Ambiente \& Água, v. 9, n. 4, pp. 679-687, 2014.

[8] INSTITUTO BRASILEIRO DE GEOGRAFIAE ESTATÍSTICA - IBGE. Pesquisa Nacional de Saneamento Básico 2008. Rio de Janeiro. Brasil, 2010.

[9] BRASIL. Lei no 9.605, de 12 de fevereiro de 1998. Dispõe sobre as sanções penais e administrativas derivadas de condutas e atividades lesivas ao meio ambiente, e dá outras providências. Diário Oficial da União, Brasília, DF, 13 fev. 1998.

[10] United Nations Conference on Environment \& Development, DIVISION FOR SUSTAINABLE DEVELOPMENT GOALS, https://sustainabledevelopment.un.org/content/documents/ Agenda21.pdf. Acessado em fevereiro de 2019.
[11] VITORINO, J.P.D., MONTEIRO, S.N., VIEIRA, C.M.F., "Caracterização e incorporação de resíduos provenientes de estação de tratamento de água em cerâmica argilosa", Cerâmica, v. 55, n.336, pp. 385-392, dez. 2009.

[12] VIEIRA, C.M.F., MARGEM, J.I., MONTEIRO, S.N., "Alterações microestruturais de cerâmica argilosa incorporada com lodo de ETA", Revista Matéria, v. 13, n. 2, pp. 275-281, Jun. 2008.

[13]SOUZA, A. E., Argilominerais: Influência dos Aditivos (Cinza de Bagaço de Cana-de-açúcar e Rocha Sedimentar) no Processo de Sinterização, Dissertação de Mestrado em Ciência e Tecnologia de Materiais, POSMAT/UNESP, Bauru, SP, Brasil, 2008.

[14] SANTOS, C. P., OLIVEIRA, H. A., OLIVEIRA, R. M. P. B., MACEDO, Z. S., "Caracterização de argilas calcárias utilizadas na produção de revestimentos cerâmicos no Estado de Sergipe - Brasil”, Cerâmica, v. 62, n. 362, pp.147-156, jun., 2016.

[15]MONTEIRO, S.N., ALEXANDRE, J.J., MARGEM, J.I., SANCHES, R., VIEIRA, C.M.F., "Incorporation of sludge waste from water treatment plant into red ceramic", Construction and Building Materials, v. 22, Materials, n. 6, pp. 1281-1287, Jun. 2008.

[16] SANTOS, P.S., Ciência e Tecnologia de Argilas, 2 ed., v. 1, São Paulo, Editora Edgard Blücher Ltda, 1989.

[17] ASSOCIAÇÃO BRASILEIRA DE NORMAS TÉCNICAS. NBR 7170: Tijolo maciço cerâmico para alvenaria. Especificação. Rio de Janeiro, 1983. 4p.

[18] TARTARI, R., Incorporação de lodo gerado na estação de tratamento de água tamanduá, como aditivo em massas para cerâmica vermelha, Dissertação de Mestrado em Engenharia Química, Centro de Engenharias e Ciências Exatas, Universidade Estadual do Oeste do Paraná, Toledo, PR, Brasil, 2008.

[19] ASSOCIAÇÃO BRASILEIRA DE NORMAS TÉCNICAS. NBR 15270-1: Componentes cerâmicos - Parte 1: Blocos cerâmicos para alvenaria de vedação - Terminologia e requisitos. Rio de Janeiro, 2005, 15 p. 